\title{
Characteristics of peripheral white blood cells in COVID-19 patients revealed by a retrospective cohort study
}

\author{
Xunliang Tong ${ }^{1}$, Anqi Cheng ${ }^{2,3,4,5}$, Xueting Yuan ${ }^{6}$, Xuefeng Zhong ${ }^{1}$, He Wang ${ }^{1}$, Wei Zhou' ${ }^{1}$, Xiaomao Xu ${ }^{1 *}$ and
} Yanming $\mathrm{Li}^{1 *}$

\begin{abstract}
Background: Peripheral hematological changes in severe COVID-19 patients may reflect the immune response during SARS-CoV-2 infection. Characteristics of peripheral white blood cells as early signals were needed to be investigated for clarifying its associations with the fatal outcomes in COVID-19 patients.

Methods: A retrospective cohort study was performed and the hospitalized COVID-19 patients were recruited in wards of Sino-French New City Branch of Tongji Hospital in Wuhan, Hubei province, China. Characteristics of peripheral white blood cells in survivors and non-survivors were analyzed. Comparison among patients with different level of eosinophils was performed.

Results: Of 198 patients included in this study, 185 were discharged and 13 died. Levels of eosinophils, lymphocytes and basophils in non-survivors were significantly lower than those in survivors. Death rate in low eosinophils group was higher and no patient died in normal eosinophils group ( $16.7 \%$ vs $0, P<0.001)$. The proportion of patients in low eosinophils group who used glucocorticoids was higher than in normal eosinophils group, but glucocorticoids usage was not an indicator for death in subgroup analysis in low eosinophils patients. Moreover, positive correlation was found between the counts of lymphocytes and eosinophils in patients with glucocorticoids use but not in patients without the treatment.

Conclusions: Hematological changes differed between survivors and non-survivors with COVID-19. Lymphopenia and eosinopenia could be predictors for poor prognosis of COVID-19 patients. Initial counts of eosinophils may guide us in usage of glucocorticoids for COVID-19 treatment.
\end{abstract}

Keywords: COVID-19, Lymphocytes, Eosinophils, Prognosis, Immune response

\section{Background}

The outbreak of COVID-19 caused by severe acute respiratory syndrome coronavirus 2 (SARS-CoV-2) has rapidly spread throughout the world $[1,2]$. The clinical manifestation of COVID-19 could specifically display in a

\footnotetext{
*Correspondence: xuxiaomaobjyy@163.com; lymyl@263.net

1 Department of Pulmonary and Critical Care Medicine, Beijing Hospital, National Center of Gerontology; Institute of Geriatric Medicine, Chinese Academy of Medical Sciences, Beijing, People's Republic of China Full list of author information is available at the end of the article
}

wide spectrum, which is so far mostly mild and self-limiting. Besides, other COVID-19 patients show severe viral pneumonia with respiratory dysfunction, even including several organs failure, resulting in a $2 \%$ to $3 \%$ mortality rate worldwide [3].

With advanced knowledge, immune system dysfunction triggered by SARS-CoV-2 was observed in COVID-19 patients. In mild cases, immune responses were efficiently established to curb the viral replication, while in severe cases, uncontrolled inflammation and 
the microcirculation dysfunctions together lead to viral sepsis with immunologic impairment [4]. The severity of disease was associated with immunological impairment. Especially, in some life-threaten cases, SARS-CoV-2 could trigger catastrophic damage to the human immune system resulting in death at their worst.

Unfortunately, our understanding of immune response to SARS-CoV-2 is extremely limited until now. Many scholars speculated that the interaction of SARS-CoV-2 and host could be referring to the other coronavirus because of the highly similarity in the sequence homology in coronavirus family [5]. Previous study mainly focused on the immune dysfunction caused by severe acute respiratory syndrome coronavirus (SARS-CoV) and Middle East respiratory syndrome coronavirus (MERS-CoV), respectively. Coronavirus infections (SARS and MERS) are confirmed to activate both innate and adaptive immune responses [6, 7]. In simply it means that the changes of peripheral blood cells could reflect the immune damage caused by virus infection.

Lymphocytes play a crucial role in maintaining immune homeostasis during virus infection, especially SARS-CoV-2 [8]. Several cohort studies have reported that lymphopenia can predict prognosis in COVID-19 patients $[9,10]$. In addition, a few studies found that the eosinopenia was also associated with poor prognostic features $[11,12]$. Thus, the differentiation of peripheral white blood cells may indicate the immunologic impairment at the early stage of the disease. However, the risk factors for the changes of peripheral blood cells, especially eosinophils (EOS) in the prognosis have not been well addressed yet. This retrospective cohort study was performed to assess the value of peripheral white blood cells in COVID-19 patients.

\section{Methods}

\section{Study design}

Patients were diagnosed of COVID-19 according to World Health Organization interim guidance. COVID19 positivity was confirmed of nucleonic acid for SARS$\mathrm{CoV}-2$ by throat swab. As one-time supportive task led by China National Health Commission, patients who were hospitalized at designated wards in the Sino-French New City Branch of Tongji Hospital in Wuhan, Hubei province, China were under treatment by medical team from Beijing Hospital. This retrospective cohort study was implemented from Feb 8th to March 15th, 2020 and all COVID-19 patients were consecutively recruited. We excluded patients with hematological disease or a blood transfusion in a week after admission. The severity of the disease was assessed according to the Seventh Version of the Novel Coronavirus Pneumonia Diagnosis and Treatment Guidance from the National Health Commission of
China. CURB-65 score were also calculated and patients were divided into 3 groups: low risk ( $0-1$ point), intermediate risk ( 2 points) and high risk (3-5 points) [13].

The study was approved by Ethics Committee of Beijing Hospital (2020BJYYEC-046-01).

\section{Medical data extraction}

The clinical data, including demographics information; clinical symptoms and signs; underlying diseases; laboratory results; the most intense level of oxygen support; treatment and clinical outcomes, were extracted from electronic medical records. The whole laboratory evaluation consisted complete blood cell counts, biochemi$\mathrm{cal}$ and coagulation indices and so forth. The differential peripheral blood indices were detailed recorded. Laboratory data at baseline were recorded in the first $24 \mathrm{~h}$ after admission According to the level of circulating EOS counts on admission, COVID-19 patients were divided into two groups: low EOS group $\left(<0.02 \times 10^{9} / \mathrm{L}\right)$ and normal EOS group $\left(\geq 0.02 \times 10^{9} / \mathrm{L}\right)$. The end point was written of discharging from hospital or death. The differences in clinical characteristics and laboratory findings in patients with different outcome would be addressed. Longitudinal tracing of laboratory indices during the hospitalization was performed and the endpoint laboratory examinations were performed. All the data were entered into a computerized database and checked by two experienced physicians independently.

\section{Statistical analysis}

Continuous variables were described using median and interquartile range (IQR). Categorical variables were described as number (\%). Non-normal distributed continuous data were compared using Mann-Whitney-Wilcoxon test. Categorical data were compared using $X^{2}$ test or the Fisher exact test. Correlations between variables were analyzed using the Spearman's rank correlation. Correlation strength was selected by an absolute correlation $|r|>0.2$ and the selected correlation were plotted as an undirected network graph. All tests were 2-sides, and a $P$ value $<0.05$ was considered statistically significant. Data was analyzed using IBM SPSS Statistics software (version 19.0).

\section{Results}

\section{Demographic information and laboratory findings at baseline of survivors and non-survivors}

A total of 198 patients confirmed severe COVID-19 were enrolled in this study. According to the clarified outcome (discharged or deceased), patients were divided in two groups: survivors and non-survivors. The median age of patients and the gender distribution between two groups (survivor group and non-survivor group) was basically 
the same. Majority of the included patients in both two groups were with comorbidity and more than half of the patients had at least one underlying disease. The ranking of the underlying disease was hypertension (40.0\%), diabetes $(16.7 \%)$, chronic respiratory diseases $(5.7 \%)$, cardiovascular diseases (5.2\%) and so on. Among the underlying disease, the percentage of malignant disease of patients in the non-survivor group is higher than it in the other group. But these patients with malignancy were all in stable stage and hadn't received any relevant surgical or chemotherapy treatment within three months. The commonest symptoms on admission were fever and cough, followed by fatigue and sputum production in both two groups. All these information was listed in Table 1.

Hematologic profile on admission varied among patients between survivor and non-survivor groups. Compared to survivors, the counts of eosinophils (EOS) and basophils (BASO) in non-survivors were too low to be detected. Lymphocytes (LYM), monocytes (MONO) and platelets (PLT) were considerably lower in non-survivors compared with survivors. (LYM: $10.9 \%$ vs $24.5 \%$, $P<0.05$; MONO: $5.9 \%$ vs $8.7 \%, P<0.05$; PLT: $145[76$, $241] \times 10^{9} / \mathrm{L}$ vs $\left.232[171,305] \times 10^{9} / \mathrm{L}, P<0.05\right)$. Level of neutrophils (NEU) and the ratio of neutrophils-tolymphocytes ratio (NLR) were significantly higher in non-survivors than survivors at baseline (NEU: $83.6 \%$ vs $65.5 \%, P<0.05$; NLR: 8.43 vs $3.05, P<0.05)$. The percentage alteration was in consistent with the absolute counts change for each analyzed peripheral blood cells. Moreover, compared with survivors, levels of $\mathrm{C}$-reactive protein (CRP), IL-6, and serum ferritin were significantly higher in non-survivors with statistical differences. Regarding the coagulation parameters, the prolonging of PT and increased levels of D-dimer were significantly higher in non-survivors compared to survivors (Table 1; Fig. 1).

\section{Treatment after enrollment and outcomes of COVID-19 patients}

During hospitalization, the most intense level of oxygen support was recorded. Patients in survivor group were mostly under oxygen therapy by nasal cannula compared to patients in non-survivor group ( $47 \%$ vs $0, P<0.05)$. The proportion of patients under invasive ventilation (IMV) in non-survivors was significantly higher than that in the other group $(53.8 \%$ vs $2.2 \%, P<0.05)$. More than $70 \%$ of the patients received antivirals, and Lopinavir/Ritonavir usage differed significantly between non-survivors and survivors $(6.7 \%$ vs $100.0 \%, P<0.05)$. According to the CURB-65 score, the proportion of patients with different grade showed significant differences between the two groups. Application of systematic glucocorticoids differed significantly between non-survivors and survivors (66.7\% vs $22.5 \%, P=0.002$ ). At the end of the observing period, 185 (93.4\%) patients were discharged and 13 (6.6\%) patients died. (Table 2).

\section{Effects on clinical characteristics of different EOS levels in COVID-19 patients}

The age and gender distribution between low EOS group and normal EOS group showed no significant differences (age: $64[53,71]$ years vs $61[47,69]$ years, $P=0.126$; gender (male): $52.6 \%$ vs $48.3 \%, P=0.561$ ). The body temperature on admission in the low EOS group was significantly higher than in normal EOS group $\left(38.9\left[38.4,39.0{ }^{\circ} \mathrm{C}\right.\right.$ vs $\left.38.5[38.0,39.0]{ }^{\circ} \mathrm{C}, P=0.011\right)$ and other symptoms did not differ significantly. The distributions of CURB65 score of patients between the two groups were significantly different. The proportion of patients who used glucocorticoids in low EOS group was significantly higher than that in normal EOS group (44.8\% vs $12.5 \%$, $P<0.05)$. But in low EOS patients, the percentage of glucocorticoids usage in non-survivor group was not significantly different from that in survivor group (66.7\% vs $40.0 \%, P=0.117$, Additional file 1: Table S1). In survivor group, high level of EOS and increasing levels of EOS was detected, whether with or without glucocorticoids usage (Additional file 1 Table S2). Duration of viral shedding in two groups showed no significant difference. Moreover, death rate in the low EOS group was significantly higher and no patient died in normal EOS group ( $16.7 \%$ vs 0 , $P<0.05$ ) (Table 3).

\section{Changing features and correlation networks analysis for peripheral blood cells}

A comparison of the levels of white blood cells at both baseline and endpoint was performed. Changes of EOS, LYM and NEU levels were different between groups. From baseline to endpoint, EOS and LYM count considerably increased in survivor group, while EOS and LYM count changed little in non-survivor group. In contrast, almost unchanged level of NEU was shown in survivors. All the information above was shown in Additional file 1: Table S3. We also observed a positive correlation between the counts of NEU and MONO $(r=0.549)$, NEU and PLT $(r=0.530)$ in non-survivors on admission. Before discharge, strong correlations between counts of NEU and MONO $(r=0.771)$, NEU and EOS $(r=0.735)$, NEU and BASO $(r=0.623)$ were observed in non-survivors. Furthermore, non-survivors showed similar positive correlations between the counts of EOS and BASO $(\mathrm{r}=0.284)$ (Fig. 2).

Patients after glucocorticoids therapy showed a negative correlation between the counts of WBC and LYM $(r=-0.265)$, but a positive correlation between WBC and LYM was observed in patients without glucocorticoids therapy $(r=0.531)$. After glucocorticoids treatment, 
Table 1 Demographic and laboratory findings at baseline of COVID-19 hospitalized patients

\begin{tabular}{|c|c|c|c|c|}
\hline Characteristics & $\begin{array}{l}\text { Total } \\
(n=198)\end{array}$ & $\begin{array}{l}\text { Survivor } \\
(n=185)\end{array}$ & $\begin{array}{l}\text { Non-survivor } \\
(n=13)\end{array}$ & $P$ value \\
\hline \multicolumn{5}{|l|}{ Demographic } \\
\hline Age, median (IQR), years & $63(48,69)$ & $62(48,69)$ & $68(58,84)$ & 0.065 \\
\hline Gender, Male, n (\%) & $99(50.0 \%)$ & $90(48.6 \%)$ & $9(69.2 \%)$ & 0.251 \\
\hline Smoking, n (\%) & $6(3.1 \%)$ & $6(3.3 \%)$ & 0 & 1.000 \\
\hline \multicolumn{5}{|l|}{ Comorbidities, n (\%) } \\
\hline Chronic respiratory disease & $11(5.7 \%)$ & $11(6.1 \%)$ & 0 & 1.000 \\
\hline Malignancy & $7(3.6 \%)$ & $4(2.2 \%)$ & $3(23.1 \%)$ & 0.007 \\
\hline Hypertension & $76(40.0 \%)$ & $72(40.7 \%)$ & 4(30.8\%) & 0.568 \\
\hline Diabetes & $32(16.7 \%)$ & $30(16.8 \%)$ & $2(15.4 \%)$ & 1.000 \\
\hline Cardiovascular disease & $10(5.2 \%)$ & $9(5.0 \%)$ & $1(7.7 \%)$ & 0.513 \\
\hline Chronic kidney disease & $6(3.1 \%)$ & $6(3.4 \%)$ & 0 & 1.000 \\
\hline \multicolumn{5}{|l|}{ Signs and symptoms, n (\%) } \\
\hline Fever & $153(79.7 \%)$ & $142(79.3 \%)$ & $11(84.6 \%)$ & 1.000 \\
\hline Chills/shivers & $42(21.2 \%)$ & $40(21.6 \%)$ & $2(15.4 \%)$ & 0.739 \\
\hline Cough & $124(64.9 \%)$ & $117(65.7 \%)$ & $7(53.8 \%)$ & 0.386 \\
\hline Productive cough & $61(31.9 \%)$ & $57(32.0 \%)$ & $4(30.8 \%)$ & 1.000 \\
\hline Chest pain/chest congestion & $38(19.9 \%)$ & $35(19.7 \%)$ & $3(23.1 \%)$ & 0.725 \\
\hline Dyspnea & $66(34.6 \%)$ & $61(34.3 \%)$ & $5(38.5 \%)$ & 0.759 \\
\hline Diarrhea & $57(29.7 \%)$ & $54(30.2 \%)$ & $3(23.1 \%)$ & 0.758 \\
\hline Fatigue or myalgia & $83(41.9 \%)$ & $77(41.6 \%)$ & $6(46.2 \%)$ & 0.749 \\
\hline CURB-65 & & & & $<0.001$ \\
\hline $0-1$ & $170(86.7 \%)$ & $170(92.9 \%)$ & 0 & \\
\hline 2 & $14(7.1 \%)$ & 13(7.1\%) & $1(7.7 \%)$ & \\
\hline $3-5$ & $12(6.1 \%)$ & $0(0)$ & $12(92.3 \%)$ & \\
\hline \multicolumn{5}{|l|}{ Laboratory findings } \\
\hline \multicolumn{5}{|l|}{ Hematologic } \\
\hline White blood cells, $\times 10^{9} / \mathrm{L}$ & $5.46(4.19,7.10)$ & $5.42(4.17,6.83)$ & $6.73(3.93,9.37)$ & 0.248 \\
\hline Neutrophils, $\times 10^{9} / \mathrm{L}$ & $3.43(2.43,4.81)$ & $3.36(2.40,4.66)$ & $5.58(2.99,8.41)$ & 0.024 \\
\hline Neutrophil percentage, $\%$ & $66.5(55.6,74.0)$ & $65.5(55.4,73.1)$ & $83.6(76.4,89.8)$ & $<0.001$ \\
\hline Lymphocytes, $\times 10^{9} / \mathrm{L}$ & $1.02(0.78,1.52)$ & $1.08(0.78,1.57)$ & $0.50(0.33,0.82)$ & $<0.001$ \\
\hline Lymphocyte percentage, $\%$ & $23.4(15.1,31.6)$ & $24.5(16.0,32.8)$ & $10.9(5.25,16.9)$ & $<0.001$ \\
\hline Lymphocytes < $0.8 \times 10^{9} / \mathrm{L}, \mathrm{n}(\%)$ & $75(37.9 \%)$ & $65(35.1 \%)$ & $10(76.9 \%)$ & 0.005 \\
\hline Neutrophil-to-lymphocyte ratio & $3.15(1.80,5.59)$ & $3.05(1.76,5.17)$ & $8.43(4.52,18.61)$ & $<0.001$ \\
\hline Monocytes, $\times 10^{9} / \mathrm{L}$ & $0.46(0.33,0.62)$ & $0.47(0.34,0.63)$ & $0.33(0.21,0.60)$ & 0.168 \\
\hline Monocyte percentage, $\%$ & $8.5(6.5,10.3)$ & $8.7(6.9,10.4)$ & $5.9(3.5,8.2)$ & $<0.001$ \\
\hline Eosinophils, $\times 10^{9} / \mathrm{L}$ & $0.03(0.00,0.09)$ & $0.03(0.00,0.10)$ & $0.00(0.00,0.00)$ & $<0.001$ \\
\hline Eosinophil percentage, $\%$ & $0.55(0.00,1.70)$ & $0.70(0.00,1.75)$ & $0.00(0.00,0.00)$ & $<0.001$ \\
\hline Eosinophil $<0.02 \times 10^{9} / \mathrm{L}, \mathrm{n}(\%)$ & $78(39.4 \%)$ & $65(35.1 \%)$ & 13(100.0\%) & $<0.001$ \\
\hline Basophils, $\times 10^{9} / \mathrm{L}$ & $0.01(0.01,0.02)$ & $0.01(0.01,0.02)$ & $0.00(0.00,0.01)$ & 0.001 \\
\hline Basophil percentage, $\%$ & $0.2(0.1,0.4)$ & $0.2(0.1,0.4)$ & $0.0(0.0,0.0)$ & $<0.001$ \\
\hline Red blood cells, $\times 10^{12} / \mathrm{L}$ & $4.10(3.70,4.45)$ & $4.10(3.75,4.46)$ & $3.39(1.77,4.37)$ & 0.013 \\
\hline Platelets, $\times 10^{9} / \mathrm{L}$ & $225(163,301)$ & $232(171,305)$ & $145(76,241)$ & 0.007 \\
\hline $\mathrm{PLT}<100 \times 10^{9} / \mathrm{L}, \mathrm{n}(\%)$ & $12(6.1 \%)$ & $8(4.3 \%)$ & $4(30.8 \%)$ & 0.004 \\
\hline Hemoglobin, g/L & $124(114,137)$ & $125(115,137)$ & $107(55,136)$ & 0.021 \\
\hline \multicolumn{5}{|l|}{ Biochemical test } \\
\hline Albumin, $\mathrm{g} / \mathrm{L}$ & $36(32,39)$ & $36(32,39)$ & $33(29,36)$ & 0.023 \\
\hline $\mathrm{ALT}, \mathrm{U} / \mathrm{L}$ & $22(15,39)$ & $23(15,40)$ & $19(17,33)$ & 0.482 \\
\hline AST, U/L & $27(19,38)$ & $27(19,37)$ & $47(36,58)$ & 0.005 \\
\hline Creatinine, $\mu \mathrm{mol} / \mathrm{L}$ & $70(58,86)$ & $69(58,83)$ & $99(61,114)$ & 0.019 \\
\hline
\end{tabular}


Table 1 (continued)

\begin{tabular}{|c|c|c|c|c|}
\hline Characteristics & $\begin{array}{l}\text { Total } \\
(n=198)\end{array}$ & $\begin{array}{l}\text { Survivor } \\
(n=185)\end{array}$ & $\begin{array}{l}\text { Non-survivor } \\
(n=13)\end{array}$ & $P$ value \\
\hline $\mathrm{LDH}, \mathrm{U} / \mathrm{L}$ & $261(206,328)$ & $258(205,318)$ & $400(302,674)$ & 0.001 \\
\hline \multicolumn{5}{|l|}{ Other indices } \\
\hline Erythrocyte sedimentation rate, $\mathrm{mm} / \mathrm{h}$ & $40(18,64)$ & $39(18,64)$ & $50(12,71)$ & 0.953 \\
\hline Serum ferritin, ng/mL & $522(310,893)$ & $480(308,799)$ & $1968(1520,3507)$ & 0.001 \\
\hline IL-6, pg/mL & 11.6(4.2,27.1) & $9 \cdot 3(4 \cdot 0,21.1)$ & $41.6(23.2,65.3)$ & 0.003 \\
\hline C-reactive protein, mg/L & $23.1(3.2,50.2)$ & $16.8(2.8,45.0)$ & $72.4(44.8,165.0)$ & $<0.001$ \\
\hline Troponin个, n (\%) & $24(18.0 \%)$ & $14(11.7 \%)$ & 10(76.9\%) & $<0.001$ \\
\hline NT-proBNP, pg/mL & $157(64,411)$ & $127(62,335)$ & $554(483,995)$ & $<0.001$ \\
\hline PT, s & $13.8(13.3,14.3)$ & $13.7(13.2,14.2)$ & $14.9(13.9,16.0)$ & 0.002 \\
\hline APTT, s & $39.7(36.6,43.9)$ & $39.6(36.6,43.4)$ & $45.4(37.8,47.2)$ & 0.105 \\
\hline $\mathrm{FIB}, \mathrm{g} / \mathrm{L}$ & $4.71(3.73,5.85)$ & $4.65(3.75,5.81)$ & $4.87(2.61,6.11)$ & 0.763 \\
\hline D-Dimer, $\mu \mathrm{g} / \mathrm{mL}$ & $0.91(0.46,1.80)$ & $0.76(0.46,1.67)$ & $2.01(1.10,5.10)$ & 0.009 \\
\hline D-Dimer $\uparrow, n(\%)$ & $116(63.7 \%)$ & $105(62.1 \%)$ & $11(84.6 \%)$ & 0.138 \\
\hline
\end{tabular}

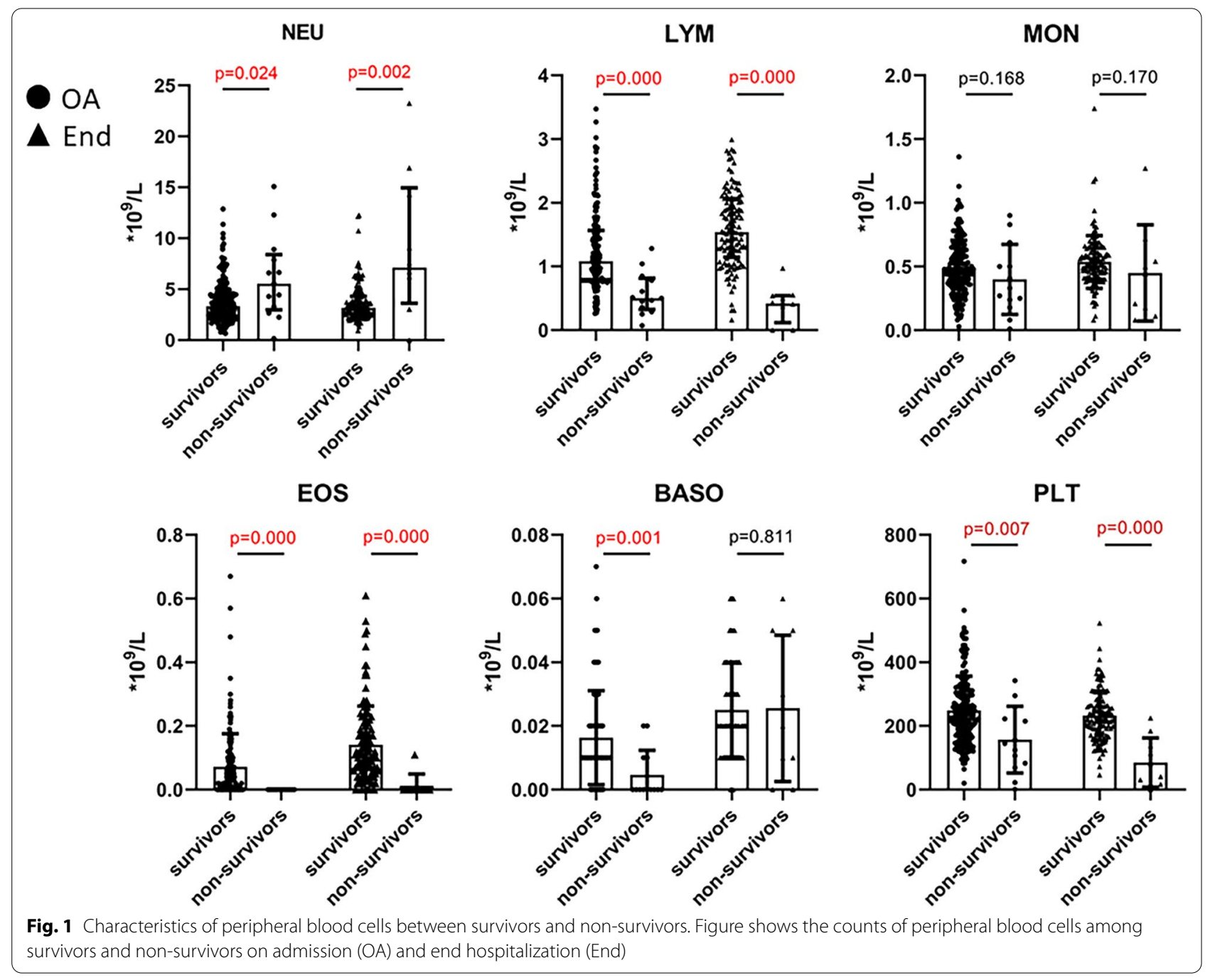


Table 2 Treatment after enrollment and outcomes of COVID-19 patients

\begin{tabular}{|c|c|c|c|c|}
\hline & $\begin{array}{l}\text { Total } \\
(n=198)\end{array}$ & $\begin{array}{l}\text { Survivor } \\
(n=185)\end{array}$ & $\begin{array}{l}\text { Non-survivor } \\
(n=13)\end{array}$ & $p$ value \\
\hline \multicolumn{5}{|l|}{ Oxygen therapy, n (\%) } \\
\hline Nasal cannula & $87(43.9 \%)$ & $87(47.0 \%)$ & 0 & $<0.001$ \\
\hline Oxygen mask & $4(2.0 \%)$ & $3(1.6 \%)$ & $1(7.7 \%)$ & 0.257 \\
\hline NMV + High-flow nasal cannula & $84(42.4 \%)$ & $79(42.7 \%)$ & $5(38.5 \%)$ & 0.576 \\
\hline IMV & $11(5.6 \%)$ & $4(2.2 \%)$ & $7(53.8 \%)$ & $<0.001$ \\
\hline ECMO & $2(1.0 \%)$ & $2(1.1 \%)$ & 0 & 1.000 \\
\hline \multicolumn{5}{|l|}{ Drugs, n (\%) } \\
\hline Oseltamivir & $60(36.4 \%)$ & $58(37.9 \%)$ & $2(16.7 \%)$ & 0.214 \\
\hline Arbidol & $121(71.2 \%)$ & $113(71.5 \%)$ & $8(66.7 \%)$ & 0.745 \\
\hline Lopinavir + Ritonavir & $23(14.2 \%)$ & $10(6.7 \%)$ & $13(100.0 \%)$ & $<0.001$ \\
\hline Ribavirin & $9(5.6 \%)$ & $8(5.4 \%)$ & $1(8.3 \%)$ & 0.672 \\
\hline Glucocorticoid & $42(25.8 \%)$ & $34(22.5 \%)$ & $8(66.7 \%)$ & 0.002 \\
\hline Hospital length of stay, days & $14(10,18)$ & $14(11,18)$ & $8(4,12)$ & $<0.001$ \\
\hline Time from illness onset to discharge, days & $27(22,34)$ & $27(23,34)$ & $20(9,28)$ & 0.005 \\
\hline
\end{tabular}

Table 3 Clinical characteristics of patients according to eosinophils level on admission

\begin{tabular}{|c|c|c|c|}
\hline & $\begin{array}{l}\operatorname{EOS}\left(<0.02 \times 10^{9} / L\right) \\
(n=78)\end{array}$ & $\begin{array}{l}\operatorname{EOS}\left(\geq 0.02 \times 10^{9} / L\right) \\
(n=120)\end{array}$ & $P$ \\
\hline EOS counts, median (IQR), $\times 10^{9} / \mathrm{L}$ & $0.00(0.00,0.00)$ & $0.08(0.04,0.15)$ & $<0.001$ \\
\hline Age, median (IQR), yrs & $64(53,71)$ & $61(47,69)$ & 0.126 \\
\hline Gender, male, n (\%) & $41(52.6 \%)$ & $58(48.3 \%)$ & 0.561 \\
\hline \multicolumn{4}{|l|}{ Signs and symptoms, n (\%) } \\
\hline Fever & $64(85.3 \%)$ & $89(76.1 \%)$ & 0.120 \\
\hline Chills/shivers & 18(23.1\%) & $24(20.0 \%)$ & 0.605 \\
\hline Cough & $46(61.3 \%)$ & $78(67.2 \%)$ & 0.403 \\
\hline Productive cough & $61(31.9 \%)$ & $22(29.3 \%)$ & 0.535 \\
\hline Chest pain/chest congestion & $16(21.3 \%)$ & $22(19.0 \%)$ & 0.689 \\
\hline Dyspnea & $26(34.7 \%)$ & $40(34.5 \%)$ & 0.979 \\
\hline Diarrhea & $17(22.7 \%)$ & $40(34.2 \%)$ & 0.088 \\
\hline Fatigue or myalgia & $28(35.9 \%)$ & $55(45.8 \%)$ & 0.166 \\
\hline Highest temperature, ${ }^{\circ} \mathrm{C}$ & $38.9(38.4,39.0)$ & $38.5(38.0,39.0)$ & 0.012 \\
\hline CURB-65, n (\%) & & & $<0.001$ \\
\hline $0-1$ & $59(76.6 \%)$ & $111(93.3 \%)$ & \\
\hline 2 & $6(7.8 \%)$ & $8(6.7 \%)$ & \\
\hline $3-5$ & $12(15.6 \%)$ & 0 & \\
\hline Glucocorticoid, n (\%) & $30(44.8 \%)$ & $12(12.5 \%)$ & $<0.001$ \\
\hline Duration of viral shedding, days & $26(21,32)$ & $26(20,33)$ & 0.753 \\
\hline Hospital length of stay, days & $15(10,18)$ & $13(11,17)$ & 0.609 \\
\hline Death, n (\%) & $13(16.7 \%)$ & 0 & $<0.001$ \\
\hline
\end{tabular}

the counts of EOS negatively correlated with NEU $(\mathrm{r}=-0.288)$, but no correlation was observed before the treatment $(r=0.058)$. A similar correlation was observed between the counts of LYM and EOS in patients received glucocorticoids therapy $(\mathrm{r}=0.454)$, but no correlation was found without the treatment $(r=0.020)$ (Fig. 3).

\section{Discussion}

As the classification of survivors and non-survivors was observed in this retrospective cohort study, the differential features of peripheral white blood cells were analyzed. Previous study demonstrated that severe patients tend to have lower lymphocytes counts, higher leukocytes counts 


\section{A OA-non-Survivors}

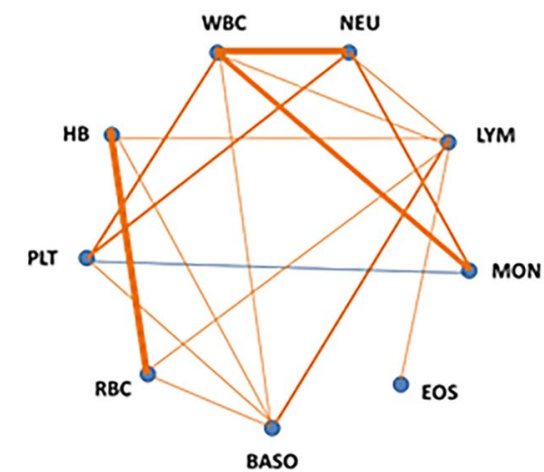

C

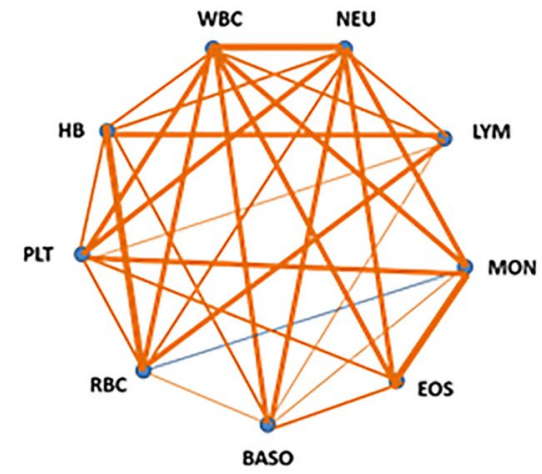

Direction positive

0.2-0.4
B

\section{OA-Survivor's}

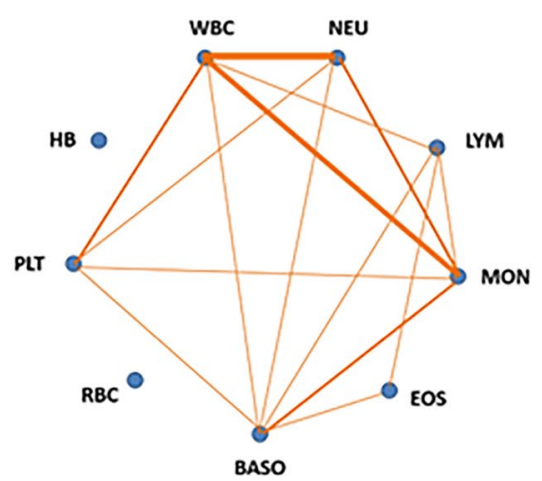

D

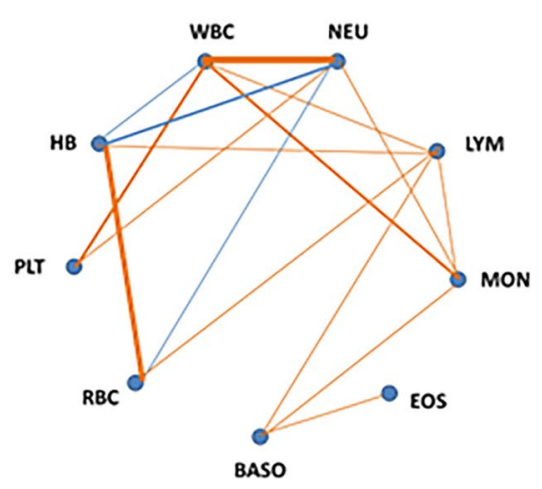

negative

\section{4-0.6}

0.6-0.8

Fig. 2 Correlation networks for peripheral blood cells among survivors and non-survivors. Networks showed different profiles of correlations in non-survivors ( $\mathbf{A}$ and $\mathbf{C}$ ) and survivors (B and $\mathbf{D})$, on admission ( $\mathbf{A}$ and $\mathbf{B}$ ) and end hospitalization $(\mathbf{C}$ and $\mathbf{D})$. The width of the edge showing stronger or weaker interactions is proportional to the absolute value of cell-cell correlation $(|r|)$. Edges were shown only when $|r|>0.2$. An orange edge indicates a positive correlation, and a blue edge indicates a negative correlation

and neutrophil-lymphocyte-ratio (NLR), as well as lymphopenia has been reported as a predictor of prognosis in COVID-19 patients $[9,14,15]$. Our data also revealed that the initial counts of lymphocytes, eosinophils, and basophils of COVID-19 patients were much lower in non-survivors compared with the counts of above indices in survivors, which was consistent with conclusion of other studies $[11,12]$.

Eosinophils are linked to immune response conferring host protection against viruses and eosinopenia has been observed in different acute inflammation situation as pneumonia [16-18]. A recent report by Xie et al. proved that COVID-19 patients with low EOS counts were likely to have more severe symptoms such as fever, fatigue, shortness of breath, more lesions in chest $\mathrm{CT}$, radiographic aggravation, longer length of hospital stay and course of disease [19]. Our study also indicated that patients with low EOS on admission showed as a predictor for in-hospital death. Eosinopenia may be the result of rapid sequestration of circulating eosinophils mediated by the overwhelming release of inflammatory cytokines, including thermogenic ones (such as IL-1, IL-6) [20]. In addition, effects of glucocorticoids on hematological and immunological indicators were significant, especially the decrease in counts of eosinophils.

Although our understanding of the specific innate and adaptive immune response to SARS-CoV-2 is relatively limited, the hematological changes may reflect a homeostatic mechanism to prevent systemic over-activation of inflammation. SARS-CoV-2 RNA and proteins interact with various pattern recognition receptors can initiate antiviral immune responses which characterized by differentiation and proliferation of various immune cells with immune mediator production and release, especially lymphocytopenia and elevated level of IL- $1 \beta$, IFN- $\gamma$, IP-10 and IL-17, regulating viral replication and 


\section{A}

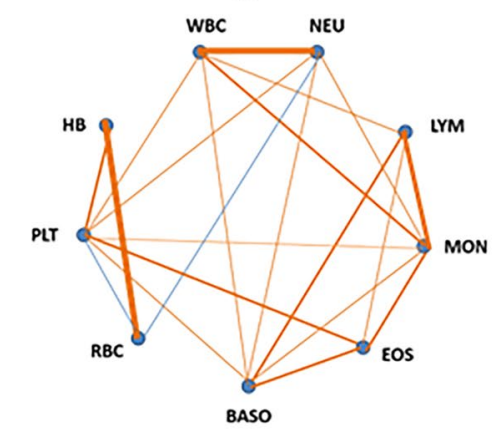

C

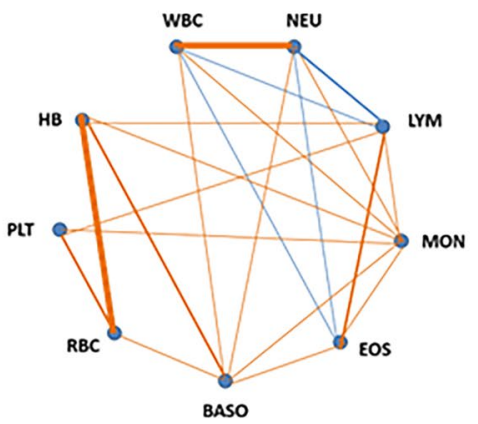

Direction _ positive

\section{$0.2-0.4$}

B

\section{OA-without glucocorticoids}

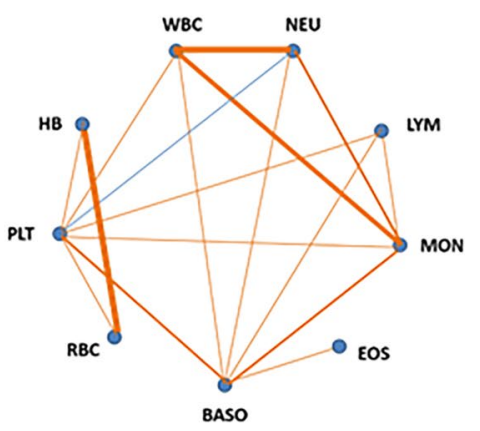

D

End- without glucocorticoids

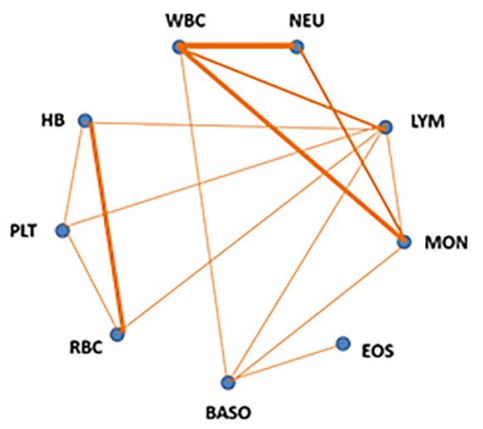

Fig. 3 Correlation networks for peripheral blood cells among patients with and without glucocorticoids. Networks showed different profiles of correlations in patients with glucocorticoids ( $\mathbf{A}$ and $\mathbf{C}$ ) and without glucocorticoids (B and $\mathbf{D})$, on admission $(\mathbf{A}$ and $\mathbf{B})$ and end hospitalization $(\mathbf{C}$ and $\mathbf{D})$. The width of the edge showing stronger or weaker interactions is proportional to the absolute value of cell-cell correlation $(|r|)$. Edges were shown only when $|r|>0.2$. An orange edge indicates a positive correlation, and a blue edge indicates a negative correlation

spreading within the host [21,22]. SARS-CoV-2 has been proven to induce remodeling of peripheral lymphocytes, and a more robust humoral immune response occurs in severe infection [23]. The decreased production, apoptosis and redistribution of lymphocytes may together lead to circulating lymphopenia [24]. In addition, eosinophils are recruited from the blood circulation into the inflammatory focus, modulating immune responses through releasing a serious of cytokines and other mediators, as well as by a broad spectrum of immune mechanisms [25]. In short, uncontrolled SARS-CoV-2 infection and the immune response may cause a systemic destruction, while the changes of peripheral blood cells can serve as early signals of immune impairment in COVID-19 patients [26].

Glucocorticoids can avoid excessive inflammation by inhibiting immune response to SARS-Cov- 2 infection, while the suppression of immunity may lead to an increase in viral load [27]. Besides, glucocorticoids can suppress the release of EOS in bone marrow and promote eosinophil clearance by directly inducing apoptosis $[28$, 29]. The panel of WHO made a strong recommendation for use of glucocorticoids in severe and critical COVID-19 patients, and in a real-life clinical setting, physicians tend to use glucocorticoids in most critically patients [30]. In this cohort, we proved that the use of glucocorticoids altered the immunological characteristics of peripheral blood cells and glucocorticoid-related EOS decreased, which was considered as a risk factor for fatal outcomes. As the role of glucocorticoids in treating severe COVID-19 patients is still controversial, blood immunological marker which could be used as an index to guide the strategy of glucocorticoids therapy in COVID-19 patients is needed and may improve the prognosis in the clinical practice.

Early identification of risk factors for critical illness can facilitate appropriate provision of supportive care and help reduce mortality. Blood routine seems like a convenient and effective indicator which can help to identify the entities involved in immune dysregulation. Lymphopenia 
and eosinopenia on admission may be particularly important to indicate the poor prognosis of COVID-19 patients, and counts of eosinophils are of guiding significance for the use of glucocorticoids. Unchanged levels of EOS during monitoring and treatment also hinted the poor prognosis of COVID-19 patients. In conclusion, peripheral white blood cells may serve as early signals of disease progression, which can be chosen as convenient and effective monitor parameters during the treatment of COVID-19.

\begin{abstract}
Abbreviations
APTT: Activated partial thromboplastin time; BASO: Basophils; CRP: C-reactive protein; COVID-19: Coronavirus disease 2019; EOS: Eosinophils; FIB: Fibrinogen; IQR: Interquartile range; LDH: Lactate dehydrogenase; LYM: Lymphocytes; MV: Mechanical ventilation; MERS-CoV: Middle east respiratory syndrome; MONO: Monocytes; NMV: Noninvasive methods of mechanical ventilation; NT-proBNP: $\mathrm{N}$-terminal pro brain natriuretic peptide; NEU: Neutrophils; PT: Prothrombin time; RT-PCR: Real-time reverse transcriptase polymerase-chain reaction; SARS-CoV: Severe acute respiratory syndrome; SARS-CoV-2: Severe acute respiratory syndrome coronavirus; WBC: White blood cell; WHO: World Health Organization.
\end{abstract}

\section{Supplementary Information}

The online version contains supplementary material available at https://doi. org/10.1186/s12879-021-06899-7.

Additional file 1: Table S1. Effect of glucocorticoids on outcome of lowEOS patients. Table S2. Effects of EOS count on survival in groups divided by glucocorticoids use. Table S3. Effect of peripheral blood cell counts and change on clinical outcome.

\section{Acknowledgements}

The authors thank Academician Chen Wang for his guidance and assistance with this work

\section{Authors' contributions}

$Y L, X X$ and $X T$ contributed to the conception and design of the study and interpretation of the results. XT and XY drafted the manuscript. XT, XZ, HW and WZ contributed to the acquisition of the data and revision of the manuscript for important intellectual content. AC performed the statistical analysis and revised the manuscript for important intellectual content. All authors read and approved the final manuscript.

\section{Funding}

This project was supported by project Grant 81870013 from the National Natural Science Foundation of China; and Grant 7202178 from the National Natural Science Foundation of Beijing.

\section{Availability of data and materials}

The data-sets used and/or analyzed during the current study available from the corresponding author on reasonable request.

\section{Declarations}

\section{Ethics approval and consent to participate}

The study was approved by Ethics Committee of Beijing Hospital (2020BJYYEC-046-01). All methods were performed in accordance with the relevant guidelines and regulations. The need of informed consent was waived by ethics committee of Beijing Hospital for this retrospective study.

\section{Consent for publication}

Not applicable.

\section{Competing interests}

The authors declare that they have no competing interests.

\section{Author details}

'Department of Pulmonary and Critical Care Medicine, Beijing Hospital, National Center of Gerontology; Institute of Geriatric Medicine, Chinese Academy of Medical Sciences, Beijing, People's Republic of China. ${ }^{2}$ Tobacco Medicine and Tobacco Cessation Center, Center of Respiratory Medicine, China-Japan Friendship Hospital, Beijing, China. ${ }^{3}$ WHO Collaborating Center for Tobacco Cessation and Respiratory Diseases Prevention, Beijing, China. ${ }^{4}$ National Clinical Research Center for Respiratory Diseases, Beijing, China. ${ }^{5}$ Institute of Respiratory Medicine, Chinese Academy of Medical Sciences, Beijing, People's Republic of China. ${ }^{6}$ The Key Laboratory of Geriatrics, Beijing Institute of Geriatrics, Beijing Hospital, National Center of Gerontology, National Health Commission, Institute of Geriatric Medicine, Chinese Academy of Medical Sciences, Beijing, People's Republic of China.

Received: 29 May 2021 Accepted: 16 November 2021

Published online: 09 December 2021

\section{References}

1. Zhu N, Zhang D, Wang W, Li X, Yang B, Song J, et al. A novel coronavirus from patients with pneumonia in China, 2019. N Engl J Med. 2020;382:727-33.

2. World Health Organization. A public health emergency of international concern over the global outbreak of novel coronavirus declared by WHO. https:/www.who.int/emergencies/diseases/novel-coronavirus-2019/ events-as-they-happen

3. Huang C, Wang Y, Li X, Ren L, Zhao J, Hu Y, et al. Clinical features of patients infected with 2019 novel coronavirus in Wuhan, China. Lancet. 2020;395:497-506.

4. Li H, Liu L, Zhang D, Xu J, Dai H, Tang N, et al. SARS-CoV-2 and viral sepsis: observations and hypotheses. Lancet. 2020;395:1517-20.

5. Vabret N, Britton GJ, Gruber C, Hegde S, Kim J, Kuksin M, et al. Immunology of COVID-19: current state of the science. Immunity. 2020;52:910-41.

6. Yang M, Li CK, Li K, Hon KL, Ng MH, Chan PK, et al. Hematological findings in SARS patients and possible mechanisms (review). Int J Mol Med. 2004;14:311-5.

7. Chu H, Zhou J, Wong BH, Li C, Chan JF, Cheng ZS, et al. Middle east respiratory syndrome coronavirus efficiently infects human primary $T$ lymphocytes and activates the extrinsic and intrinsic apoptosis pathways. J Infect Dis. 2016;213:904-14.

8. Channappanavar R, Zhao J, Perlman S. T cell-mediated immune response to respiratory coronaviruses. Immunol Res. 2014:59:118-28.

9. Qin C, Zhou L, Hu Z, Zhang S, Yang S, Tao Y, et al. Dysregulation of immune response in patients with coronavirus 2019 (COVID-19) in Wuhan, China. Clin Infect Dis. 2020;71:762-8.

10. Li D, Chen Y, Liu H, Jia Y, Li F, Wang W, et al. Immune dysfunction leads to mortality and organ injury in patients with COVID-19 in China: insights from ERS-COVID-19 study. Signal Transduct Target Ther. 2020;5:62.

11. Wei $X$, Jiang $X$, Huang L, Pan S, Chen C, et al. Predictive value of eosinophil count on COVID-19 disease progression and outcomes, a retrospective study of Leishenshan Hospital in Wuhan, China. J Intensive Care Med. 2021. https://doi.org/10.1177/08850666211037326.

12. Cortés-Vieyra R, Gutiérrez-Castellanos S, Álvarez-Aguilar C, Baizabal-Aguirre VM, Nuñez-Anita RE, et al. Behavior of eosinophil counts in recovered and deceased COVID-19 patients over the course of the disease. Viruses. 2021;13:1675

13. Nguyen $Y$, Corre F, Honsel V, Curac S, Zarrouk V, et al. Applicability of the CURB-65 pneumonia severity score for outpatient treatment of COVID19. J Infect. 2020;81(3):e96-8.

14. Tan $L$, Wang $Q$, Zhang $D$, Ding J, Huang $Q$, Tang $Y Q$, et al. Lymphopenia predicts disease severity of COVID-19: a descriptive and predictive study. Signal Transduct Target Ther. 2020;5:33.

15. Yang X, Yu Y, Xu J, Shu H, Xia JA, Liu H, et al. Clinical course and outcomes of critically ill patients with SARS-CoV-2 pneumonia in Wuhan, China: a single-centered, retrospective, observational study. Lancet Respir Med. 2020;8:475-81. 
16. Chou A, Serpa JA. Eosinophilia in patients infected with human immunodeficiency virus. Curr HIV/AIDS Rep. 2015;12:313-6.

17. Rodrigo-Munoz JM, Sastre B, Canas JA, Gil-Martinez M, Redondo N, Del Pozo V. Eosinophil response against classical and emerging respiratory viruses: COVID-19. J Investig Allergol Clin Immunol. 2020;31(2):94-107.

18. Lavoignet CE, Le Borgne P, Chabrier S, Bidoire J, Slimani H, ChevroletLavoignet J, et al. White blood cell count and eosinopenia as valuable tools for the diagnosis of bacterial infections in the ED. Eur J Clin Microbiol Infect Dis. 2019:38:1523-32

19. Xie G, Ding F, Han L, Yin D, Lu H, Zhang M. The role of peripheral blood eosinophil counts in COVID-19 patients. Allergy. 2020;76(2):471-82.

20. Bass DA. Behavior of eosinophil leukocytes in acute inflammation. II. Eosinophil dynamics during acute inflammation. J Clin Invest. 1975;56:870-9.

21. Allegra A, Di Gioacchino M, Tonacci A, Musolino C, Gangemi S. Immunopathology of SARS-CoV-2 infection: immune cells and mediators, prognostic factors, and immune-therapeutic implications. Int J Mol Sci. 2020;21:4786.

22. Li K, Hao Z, Zhao X, Du J, Zhou Y. SARS-CoV-2 infection-induced immune responses: friends or foes? Scand J Immunol. 2020:92:e12895.

23. Zhang F, Gan R, Zhen Z, Hu X, Li X, Zhou F, et al. Adaptive immune responses to SARS-CoV-2 infection in severe versus mild individuals. Signal Transduct Target Ther. 2020;5:156.
24. Tan L, Wang Q, Zhang D, Ding J, Huang Q, Tang YQ, et al. Correction: Lymphopenia predicts disease severity of COVID-19: a descriptive and predictive study. Signal Transduct Target Ther. 2020;5:61.

25. Rosenberg HF, Phipps S. Foster eosinophil trafficking in allergy and asthma. J Allergy Clin Immunol. 2007;119:1303-10.

26. Pedersen SF, Ho YC. SARS-CoV-2: a storm is raging. J Clin Invest. 2020;130:2202-5.

27. Moran JL, Graham PL, Rockliff S, Bersten AD. Updating the evidence for the role of corticosteroids in severe sepsis and septic shock: a Bayesian meta-analytic perspective. Crit Care. 2010;14:R134.

28. Jiang S, Liu T, Hu Y, Li R, Di X, Jin X, et al. Efficacy and safety of glucocorticoids in the treatment of severe community-acquired pneumonia: a meta-analysis. Medicine. 2019;98:e16239.

29. Fulkerson PC, Rothenberg ME. Targeting eosinophils in allergy, inflammation and beyond. Nat Rev Drug Discov. 2013;12:117-29.

30. Siemieniuk RA, Bartoszko JJ, Ge L, Zeraatkar D, Izcovich A, Pardo-Hernandez $\mathrm{H}$, et al. Drug treatments for covid-19: living systematic review and network meta-analysis. BMJ. 2020;370:m2980.

\section{Publisher's Note}

Springer Nature remains neutral with regard to jurisdictional claims in published maps and institutional affiliations.
Ready to submit your research? Choose BMC and benefit from:

- fast, convenient online submission

- thorough peer review by experienced researchers in your field

- rapid publication on acceptance

- support for research data, including large and complex data types

- gold Open Access which fosters wider collaboration and increased citations

- maximum visibility for your research: over $100 \mathrm{M}$ website views per year

At BMC, research is always in progress.

Learn more biomedcentral.com/submissions 